\title{
MỘT PHƯƠNG PHÁP TIẾP CẬN MỚI TRONG PHÂN TÍCH VÀ MÔ PHỎNG QUÁ TRİNH DậP NÓNG DỤNG CỤ CẮT GỌT MÓNG/DA DỤ̂A TRÊN HỆ THỐNG CAD/CAE
}

\author{
ĐẬNG HOÀNG MINH ${ }^{(1)}$, NGUYẼ̃N PHÁT TÀI ${ }^{(2)}$, NGUYỄN VIỆT ĐỨC ${ }^{(3)}$ \\ ${ }^{(1)}$ Khoa Công nghệ Co khí, Trường Đại học Công nghiệp Thành Phố Hồ Chí Minh; \\ ${ }^{(2)}$ Khoa Kỹ thuật, Truoòng Đại học Việt Đúc; \\ ${ }^{(3)}$ Khoa Công trình, Trường Đại học Thủy Lợi; \\ danghoangminh@iuh.edu.vn,tai.np@vgu.edu.vn,ducnv@tlu.edu.vn
}

Tóm tắt. Bài báo đề xuất quy trình thiết kế, mô phỏng quá trình dập khối nóng dụng cụ kềm cắt móng và da, vốn có nhu cầu sử dụng cao trên thị trường nhóm các sản phẩm chăm sóc cơ thể. Dựa trên việc ứng dụng các phần mềm CAD/CAE với phương pháp phần tử hữu hạn, điển hình là các phần mềm DEFORM3D, KOMPAS 3D, Geomagic Design X và ANSYS, các tác giả đã xây dựng một quy trình "thiết kế-mô phỏng-phân tích" khép kín. Từ đó dự đoán được quá trình dập, xác định lực dập cùng các yếu tố ảnh hưởng, tính ứng suất dư, phân tích và xử lý nhiệt, v.v... Một số lượng lớn (60) thực nghiệm số đã được tiến hành với các yếu tố đầu vào khác nhau như kích thước phôi, nhiệt độ, vận tốc của máy dập. Các kết quả mô phỏng thu được cho phép xác định khuyết tật của sản phẩm, giúp giảm thiểu các sai sót trong quá trình thiết kế, chuẩn bị phôi, lựa chọn trang thiết bị và chế độ dập hợp lý. Công trình có ý nghĩa thực tiễn cao trong lĩnh vực định hình kim loại và các ngành công nghiệp liên quan ở nước ta.

Từ khóa. Dập khối nóng, dập/rèn nóng, định hình kim loại, $\mathrm{CAD} / \mathrm{CAE}$, phương pháp phần từ hữu hạn (FEM), DEFORM-3D

\section{A NEW APPROACH TO SIMULATION AND ANALYSIS OF HOT DIE FORMING PROCESS FOR MANUFACTURING CUTICLE NIPPER BASED ON CAD/CAE SYSTEM}

\begin{abstract}
This paper presents simulation and analysis of hot die forming process for manufacturing cuticle nipper, which is a very useful tool with high demand in the body-care product maket. Based on the application of the CAD/CAE system with finite element method (FEM) including the softwares DEFORM-3D, KOMPAS 3D, Geomagic Design X and ANSYS, the authors developed a closed-loop process "design-simulation-analysis", which helps properly to forecast forming process, determine the force with influence factors, residual stresses, heat analysis and processing, ect. Sixty numerical experiments with different input data including shape of workpieces, temperature and velocity of forging machine were carried out. The obtained simulation results allowed for indicating product defects, reducing design error, selecting hot metal preparation, machines and forging procedure suitably. Therefore, the outcome of this study has a high practical significance in the area of metal forming and related industries in Vietnam.
\end{abstract}

Keywords. Hot blocker forging, hot die-forging, metal forming, CAD/CAE, finite element method (FEM), DEFORM-3D

\section{GIỚI THIỆU CHUNG}

Gia công kim loại bằng áp lực là một phương pháp gia công cơ bản vì có thể tạo ra các sản phẩm có hình dạng và kích thước phức tạp, năng suất cao và giá thành hợp lý. Do đó, gia công áp lực (GCAL) có một vị trí rất lớn trong đời sống và kỹ thuật (Hình 1 ), ví dụ như các ngành ôtô, xe máy, cơ khí chế tạo và công nghiệp quốc phòng, v.v... Trong số các sản phẩm dân dụng được tạo ra bằng GCAL phải kể đến nhóm dụng cụ chăm sóc cơ thể, như kềm cắt móng và da (Hình 1.d), vốn có nhu cầu khá lớn từ phía người tiêu dùng, nhất là ở giai đoạn nền kinh tế thị trường phát triển và hội nhập văn hóa thẩm mỹ toàn 
cầu hiện nay. Các sản phẩm này khi được tạo ra từ GCAL, cụ thể là phương pháp dập (rèn) nóng, thường có cơ tính và độ tin cậy cao [1].

Công nghệ dập khối-nóng vốn được ra đời và không ngừng nghiên cứu ở các nước phát triển [2]. Dập (rèn) nóng là một quá trình gia công kim loại, trong đó các phôi kim loại bị biến dạng trên nhiệt độ tái kết tinh, cho phép vật liệu giữ được hình dạng bị biển dạng khi nguội (Hình 2). Rèn nóng được thực hiện bằng cách sử dụng búa thủy lực hoặc khí nén, máy ép, và các máy móc tương tự khác được sử dụng để nén kim loại nóng vào hình dạng mong muốn của nó [2]. Điều này thường đạt được bằng cách sử dụng một khuôn tùy chỉnh. Khuôn được sử dụng trong rèn nóng được tùy chỉnh sao cho phù hợp với thiết kế của sản phẩm. Bởi vì kim loại nóng có tính dẻo hơn nên phương pháp này cho phép định hình các chi tiết phức tạp hơn rèn nguội. Sau khi quá trình dập khối nóng kết thúc, các bộ phận được làm mát nhanh chóng để cố định kim loại trong hình dạng mới của nó [3], đồng thời tiến hành gia công loại bỏ các vật liệu thừa (ba via) và cải thiện chất lượng bề mặt chi tiết.

Tại Việt Nam công nghệ dập nóng vẫn còn khá hạn chế, tuy nhiên với tay nghề thủ công khéo léo và tỉ mỉ của người thợ, chúng ta vẫn tạo ra được các sản phẩm có tính mỹ thuật cao, thậm chí cạnh tranh với sản phẩm của các nước có bề dày về cơ khí như Đức, Nhật. Nhưng để sản xuất hàng loạt theo quy mô công nghiệp, với yêu cầu cao về độ bền cơ tính cũng như các chỉ tiêu kỹ thuật khác, thì hiện nay chúng ta vẫn chưa thể cạnh tranh được với các thương hiệu nổi tiếng trên thế giới. Việc nhập khẩu những sản phẩm của công nghê này từ nước ngoài thường dẫn tới những khó khăn như giá thành cao, sự lệ thuộc và tình thế bị "chiếm lĩnh" đối với thị trường trong nước của chúng ta. Theo khảo sát tổng quan của các tác giả, số lượng hạn chế các công trình trong nước về dập nóng thể hiện rằng lĩnh vực này đã chưa được nghiên cứu một cách thỏa đáng, mà điển hình như là công nghệ mô phỏng số quá trình dập khối-nóng trước khi tiến hành gia công thật [2] .

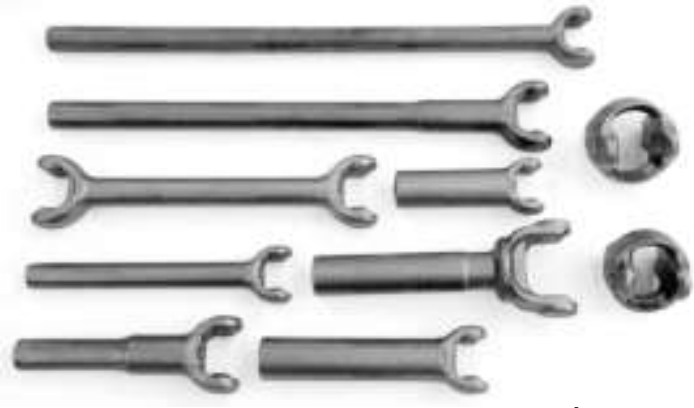

a.Phuộc với bánh răng và khớp nối

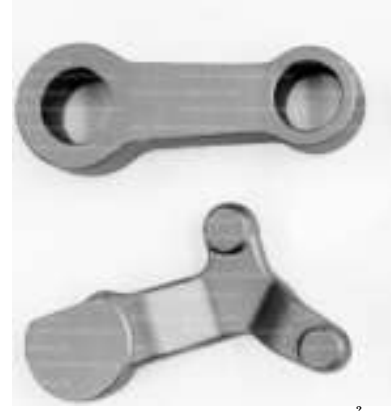

b. Mặt bích, đòn bẩy, thanh nối, giá đỡ, móc
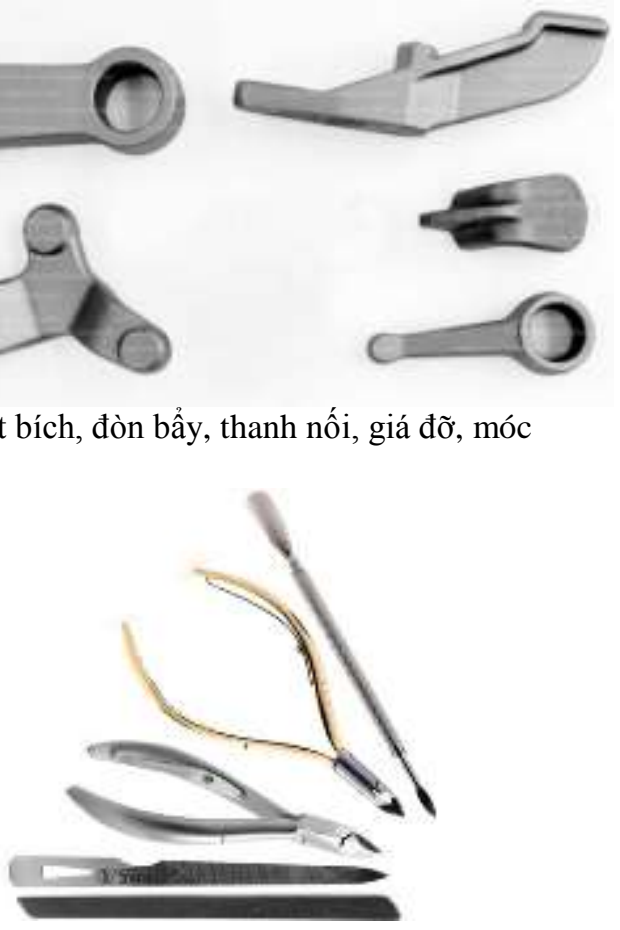

d. Các dụng cụ cắt móng và da

c. Các bánh răng

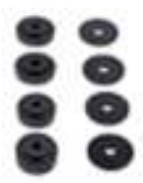

Hình 1: Các sản phẩm được tạo ra từ phương pháp gia công áp lực 

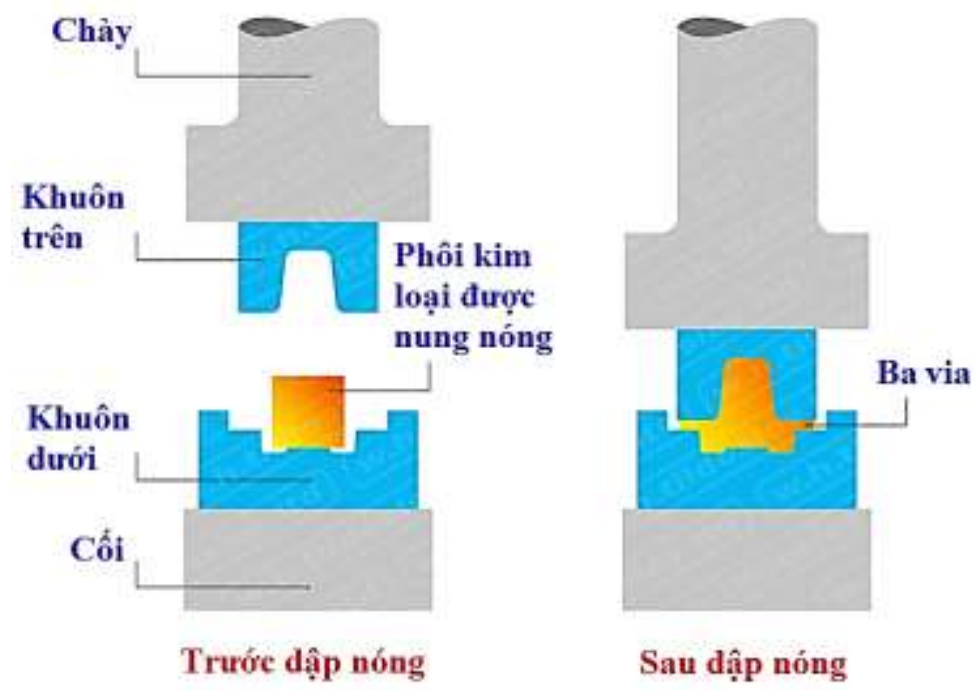

Hình 2. Nguyên lý dập (rèn) khối nóng

Trên thực tế thì mô phỏng số có thể mang lại lợi ích vì tiết kiệm chi phí và thời gian đáng kể bằng cách cung cấp cái nhìn tồng thể cũng như chi tiết về quá trình dập, trước khi lựa chọn công cụ và quyết định sản xuất ở nhà máy [4]. Chính vì vậy, việc ứng dụng các phần mềm mô phỏng hiện nay dần trở thành một xu thế tất yếu. Tuy nhiên vẫn còn tồn đọng rất nhiều khó khăn khi muốn khai thác và sử dụng chúng. Ví dụ như để xây dựng mô hình cho dập khối chuyên sâu trong ANSYS [5] và ABAQUS [6] (các phần mềm thông dụng hiện nay) là khá khó khăn và tốn nhiều thời gian. Trong công trình [7] tác giả có nghiên cứu mô phỏng quá trình dập tấm bằng PAMP-STAMP. Tuy nhiên phần mềm này lại chỉ thích ứng với việc dập tấm chứ không phải dập khối nóng. Các phần mềm như Transvalor Forge [8], Qform [9], EnginSoft [10] khá đắt đỏ và chưa phổ biến ở Việt Nam. Phần mềm DEFORM-3D [11] với giá thành không quá cao đã bước đầu được sử dụng ở các công ty trong nước. Nhưng việc xây dựng một quy trình mô phỏng cho các dụng cụ có hình dáng phức tạp và đa dạng hiện vẫn đang còn nhiều khó khăn. Bởi lẽ nó phải xuất phát từ nhiều công đoạn như thiết kế khuôn, phôi trong các phần mềm CAD khác, sau đó dẫn nhập dữ liệu để tiến hành mô phỏng. Đồng thời việc phân tích dữ liệu sau mô phỏng (CAE) là một yêu cầu chuyên sâu về mặt khoa học, bản chất vật lý mà đa số các kỹ sư ở các công ty Việt Nam hiện nay vẫn còn nhiều hạn chế [12]. Thực tế cho thấy, chỉ khi phân tích dữ liệu mô phỏng một cách thỏa đáng, thì việc mô phỏng mới thể hiện đủ ý nghĩa dự toán cho quá trình sản xuất và gia công thật.

Trên thế giới hiện nay đã có một số nghiên cứu đi sâu vào lĩnh vực ứng dụng hệ thống CAD/CAE/CAM để thiết kế, mô phỏng, chế tạo một số chi tiết dập nóng. Ví dụ như ở tài liệu [13] đã nghiên cứu vấn đề này để gia công vít, bài báo [14] thì hướng tới việc gia công vỏ điện thoại bằng hợp kim magiê. Những công trình mà ứng dụng mô phỏng để nghiên cứu chuyên sâu hơn về dập nóng, có thể kể đến như ở tài liệu [15] các tác giả đã mô phỏng và thực nghiệm dập nóng sử dụng khuôn có biên dạng hình chữ nhật và hình chiếc lá, với các điều kiện có và không có ma sát để phân tích các quy luật thay đồi tính chất vật liệu. Trong tài liệu [16] tác giả đã mô phỏng quá trình dập bánh răng côn. Đáng chú ý là kết quả mô phỏng có thể dự đoán khoảng cách cần thiết giữa 2 bề mặt khuôn và xác định sự thay đổi lực dập hợp lý trong suốt hành trình dập. Tuy nhiên, các công trình này chưa đưa ra một quy trình rõ ràng và tổng quát để có thể áp dụng cho nhiều sản phẩm đa dạng khác nhau. Chính vì vậy mà việc áp dụng chúng để chế tạo gia công dập nóng các sản phẩm kềm cắt móng và da còn gặp nhiều khó khăn. Đa số các công ty hiện nay ở Việt Nam như Kềm Sài Gòn AAA [12] vẫn còn thiếu hụt các quy trình công nghệ ứng dụng $\mathrm{CAD} / \mathrm{CAE}$ để mô phỏng và xác định thông số gia công dập phù hợp, dẫn tới phải mất khá nhiều chi phí cho những hoạt động thử nghiệm trên các thiết bị thật. Trong khi đó thì chỉ cần khi các yêu cầu của khách hàng về sản phẩm có sự thay đổi, cũng sẽ dẫn tới việc phải tiến hành lại các thử nghiệm để xác định thông số gia công mới sao cho thích hợp. Đó là tình trạng nan giải chung ở nước ta hiện nay.

Từ những luận điểm nêu trên, bài báo này sẽ đề xuất một quy trình "thiết kế-mô phỏng-phân tích" khép kín dựa trên việc ứng dụng các phần mềm $\mathrm{CAD} / \mathrm{CAE}$, điển hình là các phần mềm $\mathrm{DEFORM}-3 \mathrm{D}$, 
KOMPAS 3D, Geomagic Design X và ANSYS, từ đó cho phép dự đoán được quá trình dập nóng, xác định lực dập cùng các yếu tố ảnh hưởng, tính được ứng suất dư, phân tích và xử lý nhiệt, v.v... Quy trình này có thể giúp các công ty sản xuất dụng cụ cắt gọt móng/da của Việt Nam tiết kiệm chi phí thử nghiệm và gia công, đồng thời tạo ra được các sản phẩm có chất lượng tốt, đáp ứng các yêu cầu kỹ thuật công nghệ cao và có thể cạnh tranh được với các sản phẩm nước ngoài.

\section{QUY TRÌNH PHÂN TÍCH VÀ MÔ PHỎNG DẬP KHỐI NÓNG ÚNG DỤNG Hệ THỐNG CAD/CAE}

Như đã trình bày ở trên, hiện nay đa số các công ty sản xuất kềm cắt gọt móng/da ở nước ta đều hoạt động theo phương thức, quy trình thiết kế kiểu truyền thống (Hình 3). Xuất phát từ yêu cầu, mong muốn của khách hàng, nhà sản xuất thiết kế nên mô hình bản vẽ sản phẩm theo phương pháp kế thừa kinh nghiệm có sẵn. Dựa trên mô hình sản phẩm đầu ra này để tiếp tục thiết kế các khuôn (trên, dưới) và phôi. Sau đó là các quá trình gia công, chế tạo khuôn và phôi, dập tạo mẫu, đánh giá chất lượng của sản phẩm thu được trên các tiêu chuẩn chất lượng như ứng suất dư, độ bền cơ học, mức độ chính xác của hình dạng, kích thước, ba via, v.v... Nếu chất lượng sản phẩm mẫu chưa đạt yêu cầu, quy trình này cần được lặp lại nhiều lần cho đến khi tìm được các thông số, chế độ dập hợp lý, đáp ứng được chỉ tiêu chất lượng. Trên cơ sở đó mới có thể tiến hành sản xuất hàng loạt.

Tuy nhiên việc thử nghiệm nhiều lần thường gây tốn kém về mặt chi phí. Chính vì vậy, trong bài báo này các tác giả đề xuất một quy trình mới, mà ý tưởng chính nằm ở việc thêm vào quy trình truyền thống các công đoạn mô phỏng, ứng dụng các hệ thống $\mathrm{CAD} / \mathrm{CAE}$ để phân tích và dự đoán trước quá trình dập nóng trên máy tính (Hình 4). Trên cơ sở đó có thể tiến hành thực nghiệm số nhiều lần mà không gây tốn kém. Dựa trên kết quả tốt nhất thu được sau khi mô phỏng, nhà sản xuất mới tiến hành các công đoạn gia công, chế tạo khuôn và mẫu. Việc thử nghiệm trên mẫu sản phẩm thật có thể hoặc không cần tiến hành, tùy vào chất lượng thu được. Nếu kết quả mô phỏng sát với thực tế thì việc thử nghiệm mẫu sản phẩm được giản lược, từ đó tiết kiệm được rất nhiều chi phí sản xuất. Cụ thể các công đoạn "ứng dụng hệ thống CAD/CAE" ở hình 4 được mô tả chi tiết trong sơ đồ hình 5.

Theo đó, đầu tiên chúng ta cần sử dụng các hệ thống $\mathrm{CAD}$ để thiết kế mô hình của sản phẩm theo yêu cầu khách hàng (1). Dựa vào hình học sản phẩm ta thiết kế tiếp mô hình khuôn trên và dưới (2). Sau khi xuất ra các định dạng phù hợp, ta dẩn nhập chúng vào phần mềm mô phỏng dập nóng để tiến hành quá trình này (3). Sau khi hoàn thành, ta tiến hành phân tích kết quả sản phẩm sau dập (4) như ứng suất dư, phân bố nhiệt độ, biến dạng, v.v. Về nguyên tắc chúng là những tiêu chí để đánh giá chất lượng sản phẩm sau mô phỏng, sự phù hợp của các thông số dập. Bên cạnh đó, mô hình của chi tiết sau dập cũng được tự động hình thành trong phần mềm mô phỏng (5). Việc phân tích cơ tính của nó trước khi đưa vào sử dụng trong tương lai cần phải trải qua công đoạn tính toán CAE trong các phần mềm ứng dụng phần tử hữu hạn (7). Tuy nhiên để trích nhập mô hình chi tiết có thể cần phải trải qua một công đoạn trung gian (6), đó là chuyển tiếp mô hình vật thể sau mô phỏng thành mô hình vật thể phù hợp về mặt hình học, cũng như cấu trúc phần tử hữu hạn. Như vậy, những công đoạn với trình tự kể trên sẽ tạo thành một quy trình khép kín, cho phép nhà sản xuất tạo ra được các sản phẩm dập nóng dụng cụ cắt móng và da có chất lượng. Các phần mềm CAD có thể sử dụng như KOMPAS-3D, Pro-Engineer, SolidWork, Inventor, v.v. Quy trình thiết kế $2 \mathrm{D}$ cũng như $3 \mathrm{D}$ của chi tiết và khuôn, thì giữa các phần mềm kể trên không có sự khác biệt nào đáng kể.

Công đoạn quan trọng nhất ở quy trình này chính là mô phỏng dập khối nóng ((3) trong hình 5). Mặc dù các phần mềm mô phỏng (như Transvalor Forge, QForm, EnginSoft, v.v.) luôn có các hướng dẫn sử dụng, tuy nhiên quy trình thực hiện cho các bài toán cụ thể, với những tính chất, đặc trưng đa dạng của các vấn đề luôn cần phải được xây dựng sao cho phù hợp và có thể đáp ứng được các yêu cầu phức tạp. Trong hình 6 các tác giả đề xuất một quy trình mô phỏng dập chi tiết với phần mềm DEFORM-3D, được cho là có giao diện dễ hiểu với khá đầy đủ các tính năng cần thiết. 


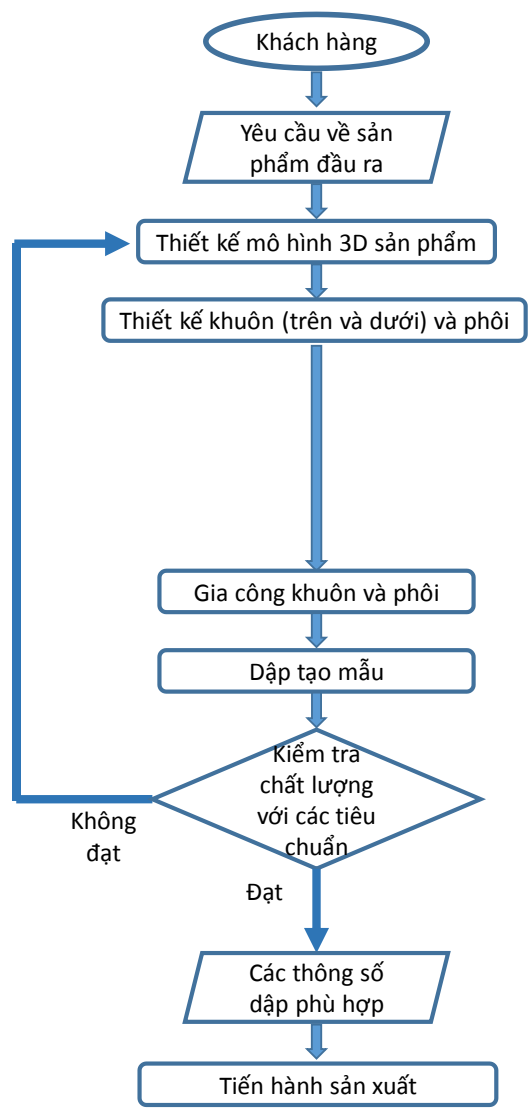

Hình 3: Quy trình thiết kế truyền thống

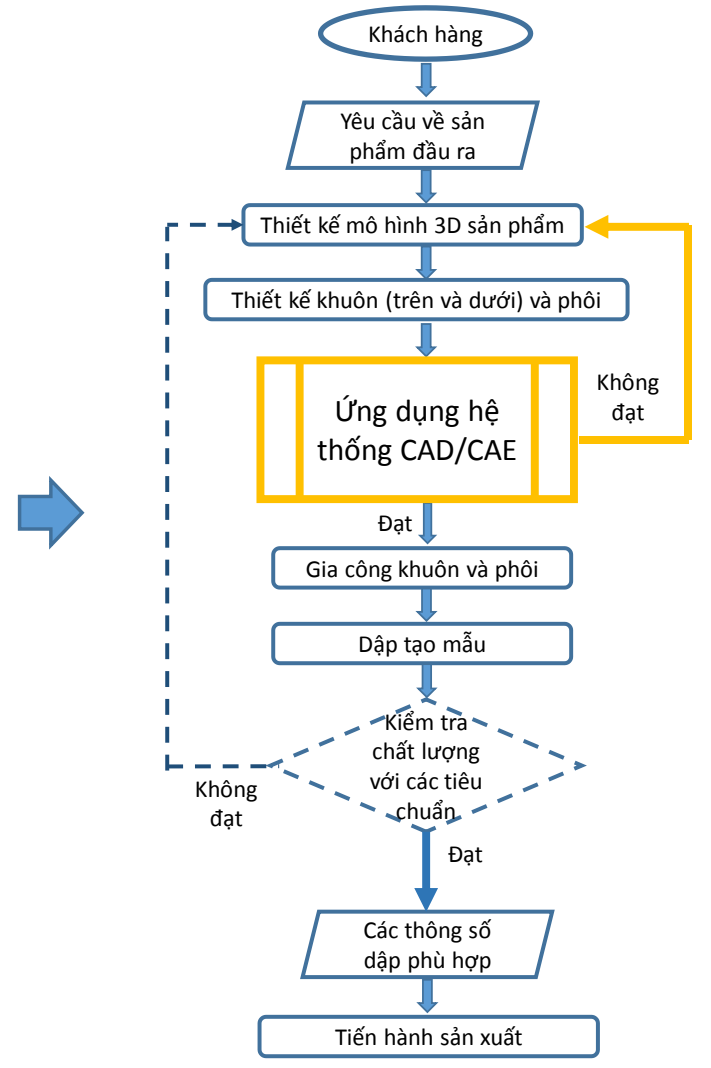

Hình 4: Đề xuất quy trình thiết kế, mô phỏng, phân tích dựa trên hệ thống $\mathrm{CAD} / \mathrm{CAE}$

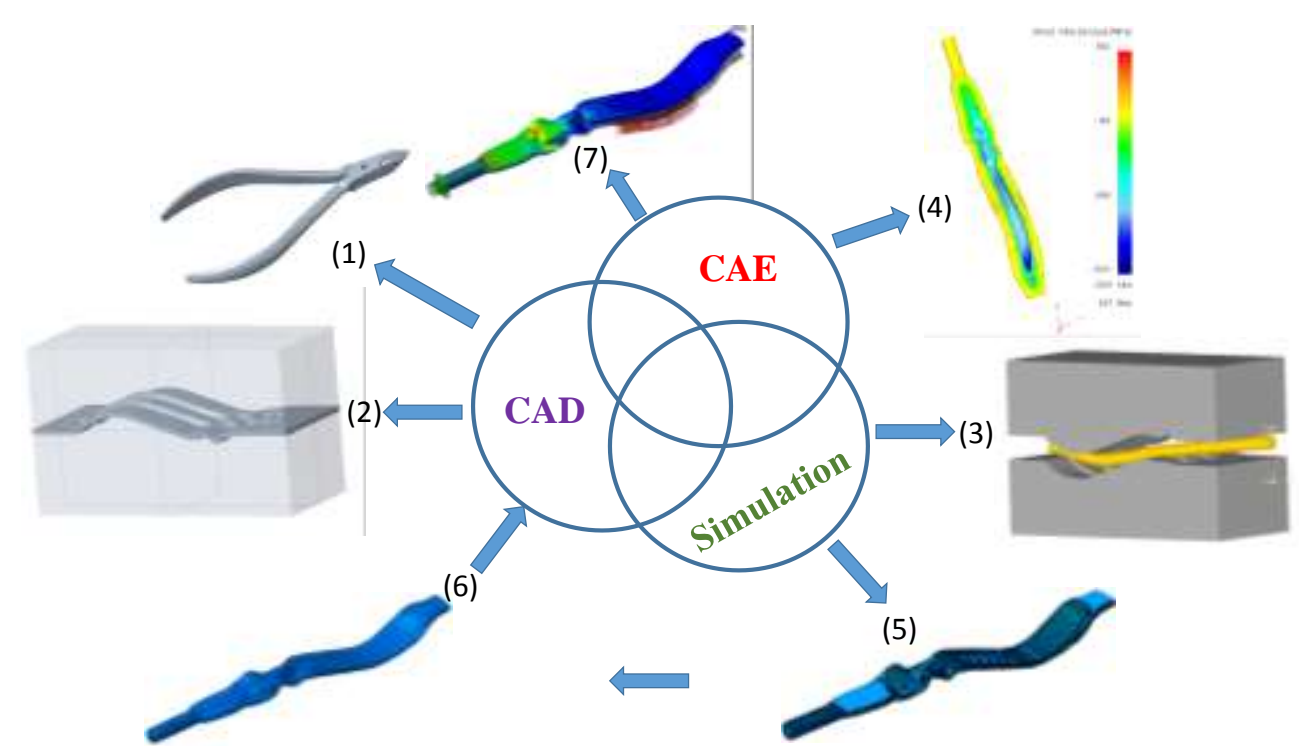

Hình 5: Các công đoạn ứng dụng hệ thống CAD/CAE trong quy trình thiết kế, mô phỏng, phân tích dập (rèn) khối nóng

Mô hình toán phần tử hữu hạn sử dụng trong DEFORM-3D là một hệ phương trình phức tạp, mô tả nhiều hiện tượng cơ-nhiệt của quá trình dập nóng như phương trình cân bằng, đặc trưng vật liệu có xét tới quán tính, trọng trường, vận tốc, ma sát, biến dạng dẻo, truyền nhiệt và các điều kiện biên. Chúng được miêu tả chi tiết trong các tài liệu [17-18]. 


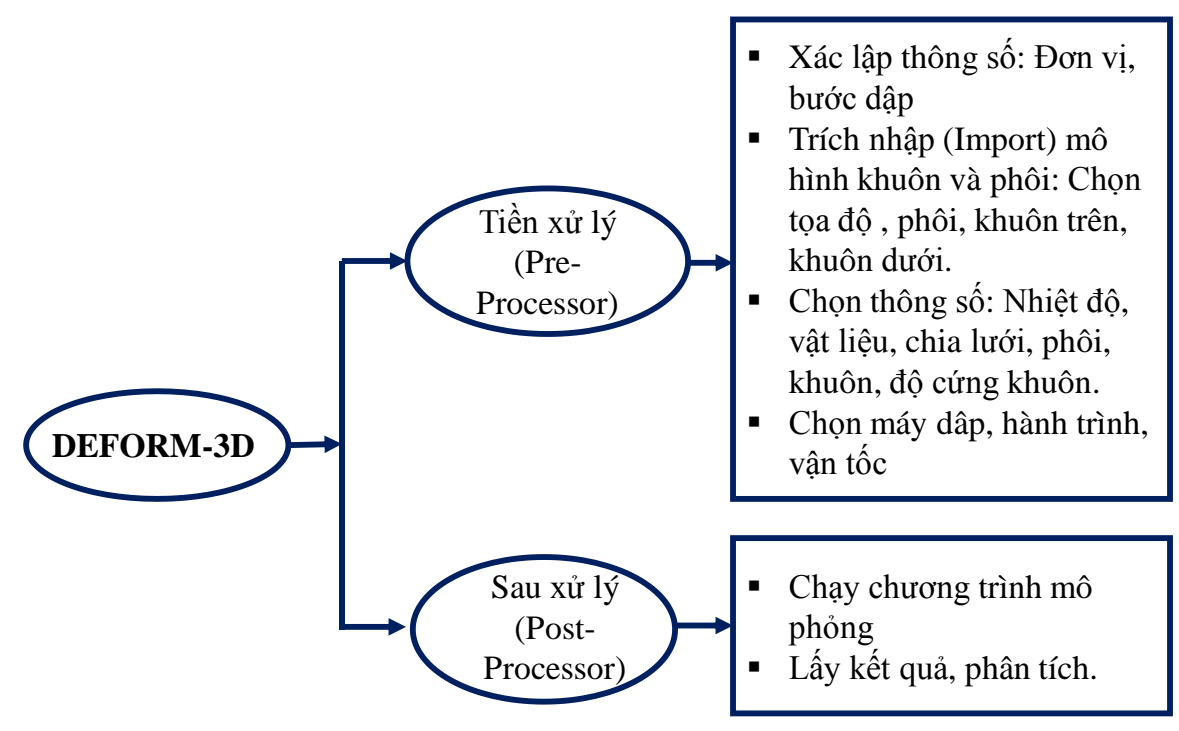

Hình 6: Quy trình mô phỏng dập trong DEFORM-3D

Với quy trình đề xuất này, sau khi mô phỏng, các dữ liệu quan trọng như biến dạng vật liệu, áp suất, áp lực và nhiệt độ dễ được thu thập bởi người dùng tại bất kỳ bước (step) nào, cũng như tại bất kỳ vị trí nào trong quá trình mô phỏng dập. Các khiếm khuyết tiềm ẩn như xếp phôi và không điền đầy vào lòng khuôn có thể dễ dàng xác định và sửa chữa trước khi bắt đầu sản xuất. Ngoài ra, có thể dễ dàng định lượng và đánh giá ảnh hưởng của các điều kiện quá trình như bôi trơn và định hình. Quá trình gia công dập chính xác được mô phỏng bằng phương pháp khối lượng hữu hạn và thiết kế hỗ trợ của công nghệ máy tính. Lực bắt buộc cho quá trình dập, cũng như hình dạng cuối cùng, được xác định thông qua ước lượng số [16] . Các kết quả mô phỏng có được thông qua việc so sánh với các dữ liệu thực nghiệm theo tiêu chuẩn.

Tiếp đến, sau khi mô phỏng quá trình dập trong DEFORM-3D, một công đoạn quan trọng nữa đó là cần phân tích độ bền cơ học của chi tiết kềm khi đưa vào sử dụng để biết được khả năng chịu tải, hệ số an toàn cũng như độ bền mỏi của nó. Tuy nhiên trong các phần mềm mô phỏng dập thường không có sẵn tính năng này, nển giải pháp duy nhất là cần xuất mô hình chi tiết sau dập để đưa vào các phần mềm tự động tính toán CAE. Vấn đề khó khăn đặt ra chính là ở mô hình chi tiết sau dập được tạo ra trong DEFORM-3D. Những mô hình sau dập này khi trích xuất ra dạng $\mathrm{CAD}$ thường là cac mồ hình hỗn độn gồm các đoạn thẳng, bề mặt cũng như vật thể khối, đó là do được tạo nên bởi quá trình phân tích biến dạng của phần tử hữu hạn. Số lượng của các phần tử khác nhau này lên đến hàng trăm ngàn nên khó có thể xử lý để kết nối các điểm nút hay đồng nhất phần tử trong quy trình phân tích FEM. Đồng thời còn tồn tại khá nhiều lỗi như thừa, thiếu các phần tử khiến cho mô hình vật thể chi tiết sau dập không thể sử dụng được trong khâu tính toán. Chính vì vậy cần phải giải quyết một công đoạn trung gian, chuyển tiếp từ mô hình sau dập để trở thành một mô hình $\mathrm{CAD}$ hoàn chỉnh ở dạng vật thể khối với bề mặt được chia lưới một cách hợp lý, thuận lợi cho quá trình đặt tải trọng cũng như các điều kiện biên.

Trong hình 7 các tác giả đề xuất một quy trình chỉnh sửa CAD của mô hình chi tiết sau dập để phù hợp cho công đoạn phân tích cơ học $\mathrm{CAE}$, sử dụng chương trình trung gian Geomagic Design X [19]. Quy trình phân tích CAE ứng xử cơ học của chi tiết hoàn toàn giống quy trình chuẩn (Hình 8): Lựa chọn vật liệu, loại phần tử hữu hạn (do chi tiết là vật thể khối, ta có thể chọn phần tử tứ diện), các thuộc tính phần tử, chia lưới, đặt tải trọng, điều kiện biên, tính toán và hậu xử lý để phân tích kết quả.

Sau khi giải hệ phương trình tuyến tính theo phương pháp phần tử hữu hạn, có 4 dạng kết quả mà giá trị của chúng có thể được coi là những tiêu chí đánh giá chất lượng của sản phẩm sau dập:

- Hệ số an toàn ở vị trí nguy hiểm nhất (có giá trị nhỏ nhất) $\rightarrow$ Cần phải cực đại hóa max

- Chuyển vị lớn nhất $\rightarrow$ Cần phải cực tiểu hóa min

- Số lần làm việc ít nhất của vị trí nguy hiểm nhất trước khi rơi vào trạng thái mỏi $\rightarrow$ Cần phải cực đại hóa $\max$ 
- Uúng suất tương đương (Von Mises) lớn nhất $\rightarrow$ Cần phải cực tiểu hóa min

Chỉ sau quá trình phân tích mô phỏng cùng các ứng xử cơ học, độ bền, độ tin cậy của sản phẩm sau dập một cách chi tiết, chúng ta mới có thể tìm ra được bộ thông số như nhiệt độ, kích thước phôi, hành trình, vận tốc dập, v.v... phù hợp. Từ đó có thể sản xuất và gia công hàng loạt.

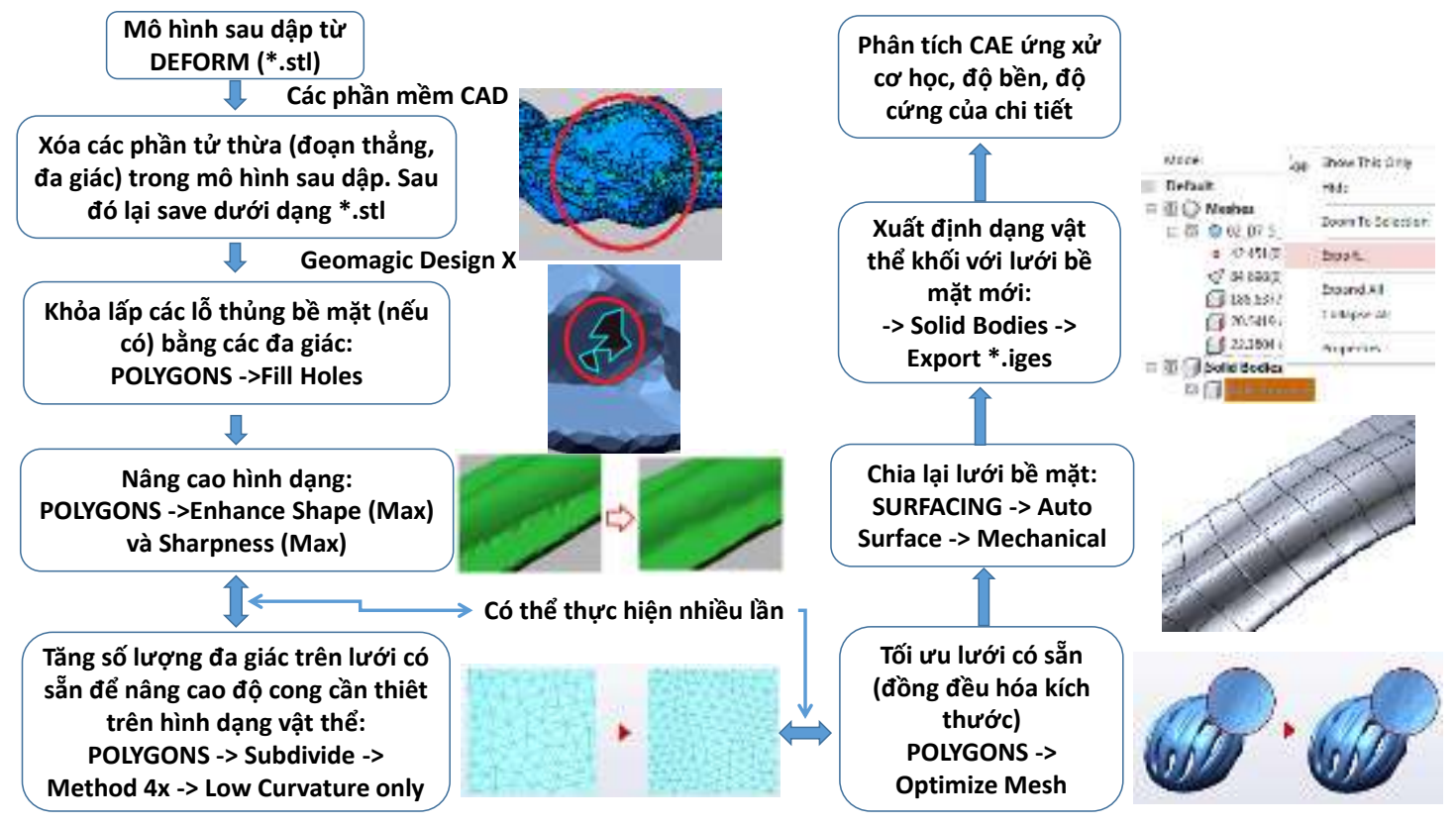

Hình 7: Quy trình chỉnh sửa mô hình $\mathrm{CAD} 3 \mathrm{D}$ của chi tiết sau mô phỏng dập để phù hợp cho việc tự động phân tích CAE

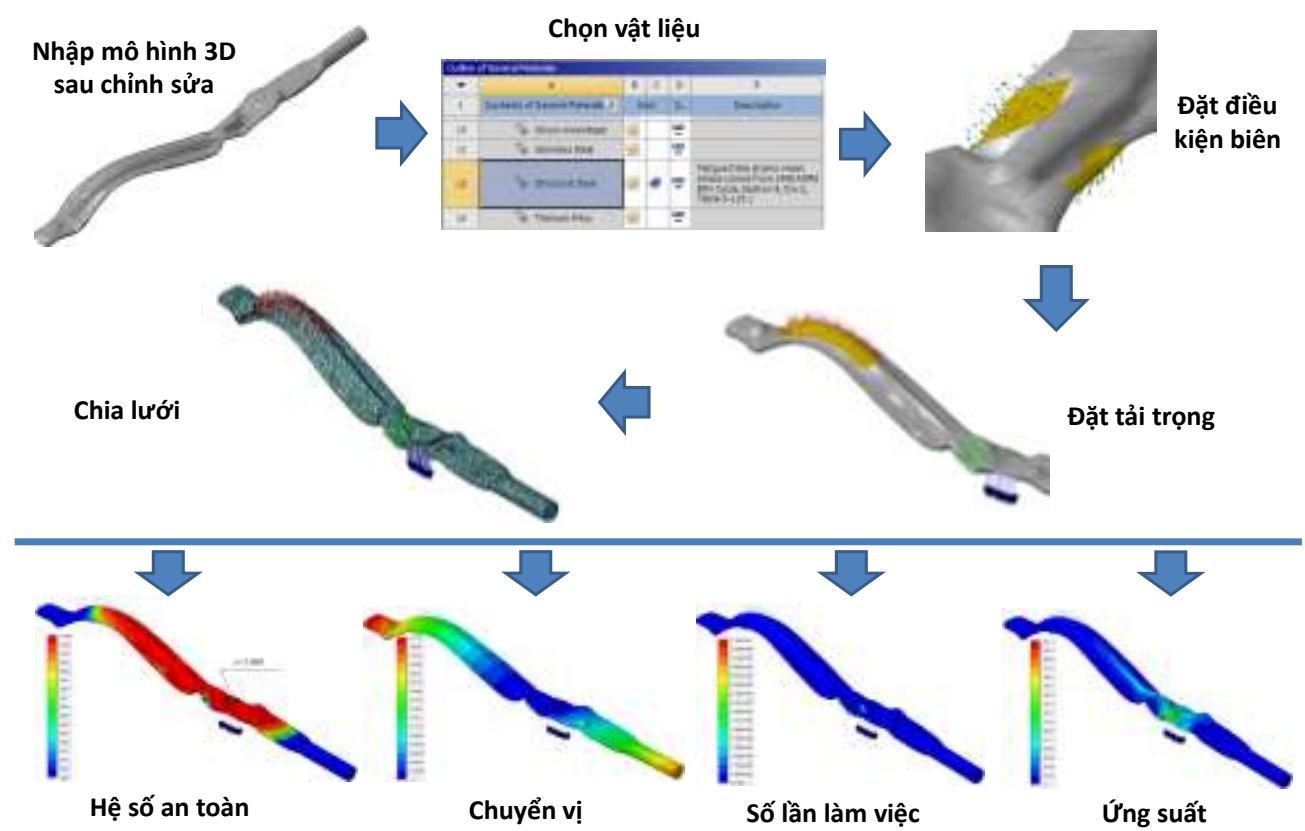

Hình 8: Quy trình phân tích CAE ứng xử cơ học của chi tiết sau dập

\section{THỰC NGHIỆM, KẾT QUẢ VÀ THẢO LUẬN}

\subsection{Mồ hình thực nghiệm số}


Với các quy trình khép kín "thiết kế-mô phỏng-phân tích" được đề xuất trong mục 2, chúng ta tiến hành thực hiện các mô phỏng số để kiểm nghiệm chúng. Mô hình thực nghiệm số được miêu tả trong hình 9 .

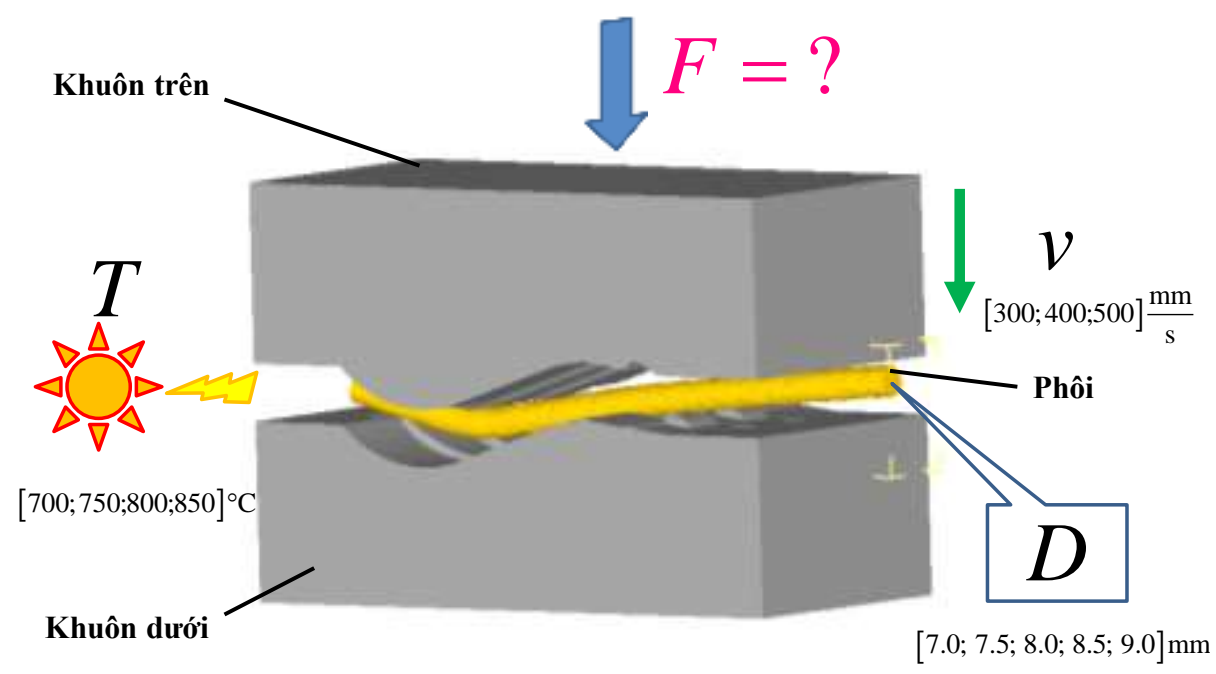

Hình 9: Mô hình thực nghiệm số

Trong khuôn khổ bài báo này, 3 thông số dập được xem xét để lựa chọn sau khi phân tích các thực nghiệm, đó là vận tốc dập $(v)$, nhiệt độ nung phôi $(T)$, đường kính phổi $(D)$ với 3 giá trị cần xét thể hiện trong bảng 1 . Ký tự “-” trong bảng thể hiện không có giá trị được xét. Những giá trị của các đại lượng này có được dựa trên kinh nghiệm có sẵn của các chuyên gia trong lĩnh vực rèn nóng. Với các giá trị xem xét trong bảng, ta có tổ hợp 60 thực nghiệm cần tiến hành mô phỏng và phân tích.

Bảng 1: Giá trị được xét của các thông số dập trong mô hình

\begin{tabular}{|c|c|c|c|c|c|}
\hline Thông số & 1 & 2 & 3 & 4 & 5 \\
\hline$v(\mathrm{~mm} / \mathrm{s})$ & 300 & 400 & 500 & - & - \\
\hline$T\left({ }^{\circ} \mathrm{C}\right)$ & 700 & 750 & 800 & 850 & - \\
\hline$D(\mathrm{~mm})$ & 7 & 7.5 & 8 & 8.5 & 9 \\
\hline
\end{tabular}

Vật liệu làm khuôn là Thép SKD61 (JIS-Nhật) hay còn gọi 40Cr5MoV (ISO), thép H13 (AISI-Mỹ), là loại thép chuyên dụng để chế tạo khuôn dập nóng, khuôn đúc với độ cứng khoảng 44-55 HRC. Loại thép này có mặt ngày một nhiều trên thị trường Việt Nam nên được lựa chọn để sử dụng. Vật liệu của kềm hay phôi là thép C45. Các tính chất cơ-lý của các vật liệu trong mô hình có thể được dễ dàng trích xuất từ trong phần mềm DEFORM-3D ở giai đoạn tiền xử lý (hình 6). Trong bài nghiên cứu này ta giả định khuôn trên và dưới cứng tuyệt đối nên không chia lưới vì độ cứng của vật liệu làm nên chúng lớn hơn rất nhiều so với phôi sau khi nung. Phôi được chia lưới bằng phần tử tứ diện 4 nút (Tetrahedral) với số lượng phần tử là 150000 . Sự lựa chọn số lượng phần tử khi chia lưới là 150000 theo phương pháp dò thử với các số lượng lần lượt là $80000,100000,120000,140000,150000,160000,180000,200000$. Nhận thấy từ sau 140000 thì các kết quả đã hội tụ, nên nhóm tác giả lựa chọn 150000 là mức chia lưới phù hợp Điều kiện biên được xác định như sau: Khuôn dưới được cố định; bề mặt khuôn trên với phôi, phôi với khuôn dưới là dạng tiếp xúc mặt.

\subsection{Phương pháp thực nghiệm số}

Thực hiện 60 thực nghiệm với các thông số dập như vừa nêu trên máy tính cá nhân có cấu hình CORE i7, RAM 16 GB. Mỗi thực nghiệm được tiến hành trong khoảng 1 giờ một cách nối tiếp, tuần tự. Thời gian thu thập các dữ liệu để phân tích khoảng 20'. Như vậy tổng chi phí thời gian cho 60 thí nghiệm nói trên là khoảng 80 giờ. 
Các thực nghiệm được đánh số thứ tự từ 1 đến 60 . Sau khi mô phỏng xong, kết hợp với các công đoạn chỉnh sửa $\mathrm{CAD}$ và phân tích độ bền cơ học $\mathrm{CAE}$, chúng ta có các giá trị và kêt quả sau:

- Lực dập $F$

- Ứng suất dư lớn nhất $(S)$

- Biến dạng

- Xếp phôi

- Mật độ

- Độ cứng vật liệu

- Hệ số an toàn khi chịu tải

- Chuyển vị lớn nhất khi chịu tải

- Số lần làm việc ít nhất trước lúc mỏi khi chịu tải

- Ứng suất tương đương lớn nhất khi chịu tải

- V.v...

Đó là những tiêu chí mà các chuyên gia và nhà sản xuất cần kiểm tra để phân tích, lựa chọn 3 thông số ở mô hình ban đầu. Trong khuôn khổ bài báo, chúng ta sẽ xem xét 2 tiêu chuẩn đầu tiên là lực dập $F$ và ứng suất dư lớn nhất $S$ sau khi mô phỏng dập, để tìm ra quy trình phân tích và ra quyết định lựa chọn thông số sản xuất hợp lý nhất. Trước hết, chúng ta cần xác định rõ về bản chất và định hướng các tiêu chí đánh giá về các thông số dập:

- Vận tốc $(v)$ : Xét về cơ tính, nếu vận tốc dập thấp thì cấu trúc của vật liệu phôi sẽ thay đổi chậm trong quá trình biến dạng. Từ đó thì chi tiết sau dập sẽ có độ bền cơ học tốt hơn trong quá trình làm việc. Tuy nhiên, nếu vận tốc dập chậm sẽ khiến quá trình này diễn ra lâu hơn, giảm hiệu suất gia công.

- Đường kính $(D)$ : Về mặt lý thuyết, nếu sử dụng phôi có kích thước nhỏ thì có thể tiết kiệm vật liệu. Tuy nhiên, có một nhược điểm là vật liệu sẽ khó điền vào đầy lòng khuôn. Điều này đòi hỏi người thợ phải đặt phôi vào khuôn một cách chính xác. Ngược lại, nếu đường kính phôi lớn thì sẽ gây hao tốn vật liệu, nhiệt lượng nung và năng lượng để chuyển đổi thành lực dập đủ mạnh.

- Nhiệt độ $(T)$ : Về mặt lý thuyết, chúng ta cần một nhiệt lượng vừa đủ để vật liệu phôi dễ định hình theo khuôn trong quá trình dập. Tuy nhiên nếu nhiệt độ quá cao sẽ gây nên lãng phí năng lượng, đồng thời có thể gây nên tình trạng biến dạng chảy, ảnh hưởng đến chất lượng sản phẩm. Vì vậy, chúng ta mong muốn nhiệt độ có giá trị nhỏ nhất.

- Lực dập $(F)$ : Cần một lực dập đủ để định hình được vật liệu. Lực dập càng lớn thì sẽ gây hao tốn năng lượng, giảm độ bền của khuôn, v.v...

- Uúng suất dư lớn nhất $(S)$ : Là ứng suất xuất hiện khi 2 lớp vật liệu/2 loại vật sát nhau/liên kết với nhau mà giữa chúng có sự không đồng nhất về cấu trúc hoặc kích thước độ hạt hoặc cơ tính (các khuôn và phôi). Nhìn chung ứng suất không có lợi cho độ bền của các chi tiết, vì vậy chúng ta luôn mong giá trị lớn nhất xuất hiện ở sản phẩm đạt giá trị nhỏ nhất có thể

\subsection{Kết quả thực nghiệm và thảo luận}

Kết quả sau mô phỏng về lực dập $F$ và ứng suất dư lớn nhất $S$ được thể hiện trong các đồ thị hình 10 và 11 . Đây có thể coi là đồ thị $4 \mathrm{D}$ với 4 thông số được thể hiện trên hình. Mỗi một điểm hình cầu/tứ diện/lục diện/hoa thị tương ứng với 1 thực nghiệm số.

Quan sát đồ thị hình 10, ta rút được ra 1 số nhận xét sau:

- Đường kính phôi và lực dập tỉ lệ thuận với nhau, không có ngoại lệ ở bất kỳ nhiệt độ nào

- Giữa lực dập và vận tốc nhìn chung cũng là mối quan hệ tỉ lẹ̣ thuận: Khi lực dập lớn thì sẽ đẩy nhanh quá trình dập. Tuy nhiên có một số điểm đặc biệt không tuân theo quy luật này, ví dụ khi ở nhiệt độ $700^{\circ} \mathrm{C}$ với các đường kính 7.5 và $7 \mathrm{~mm}$; ở nhiệt độ $750^{\circ} \mathrm{C}$ với các đường kính 7 và $8 \mathrm{~mm}$; ở nhiệt độ $800^{\circ} \mathrm{C}$ với đường kính $7 \mathrm{~mm}$; và đặc biệt khi nhiệt độ là $850^{\circ} \mathrm{C}$ thì mối tương quan tỉ lệ thuận không được rõ ràng. 


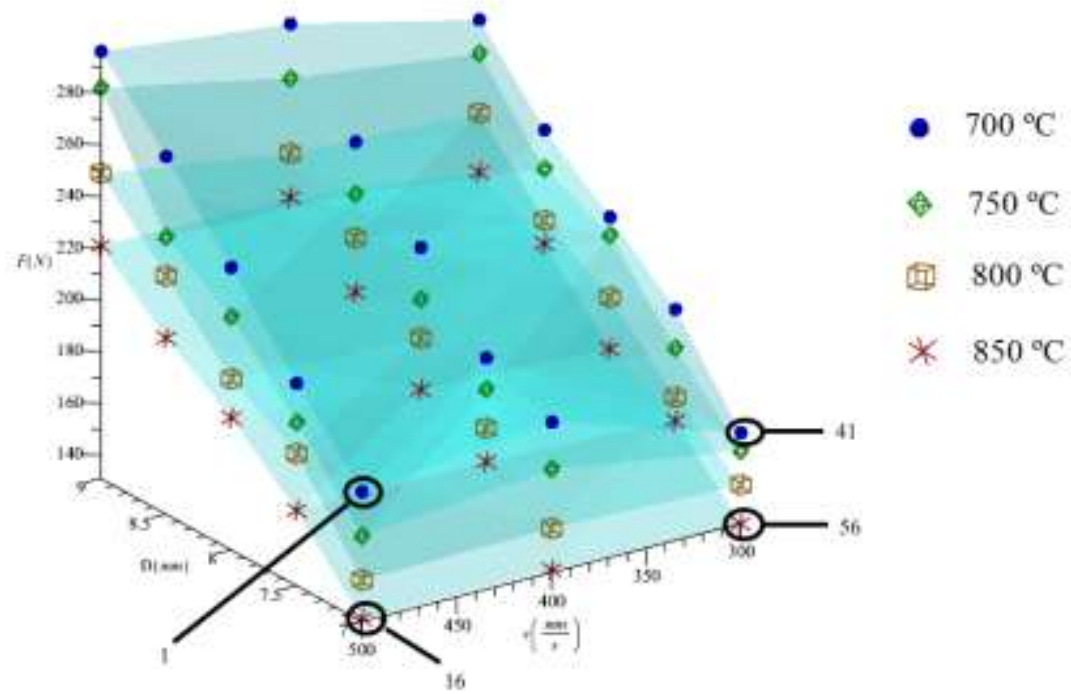

Hình 10: Đồ thị thể hiện mối quan hệ giữa 4 đại lượng phân tích: Đường kính phôi $(D)$, vận tốc dập $(\mathrm{mm} / \mathrm{s})$, nhiệt độ phôi $(T)$ và lực dập $(F)$

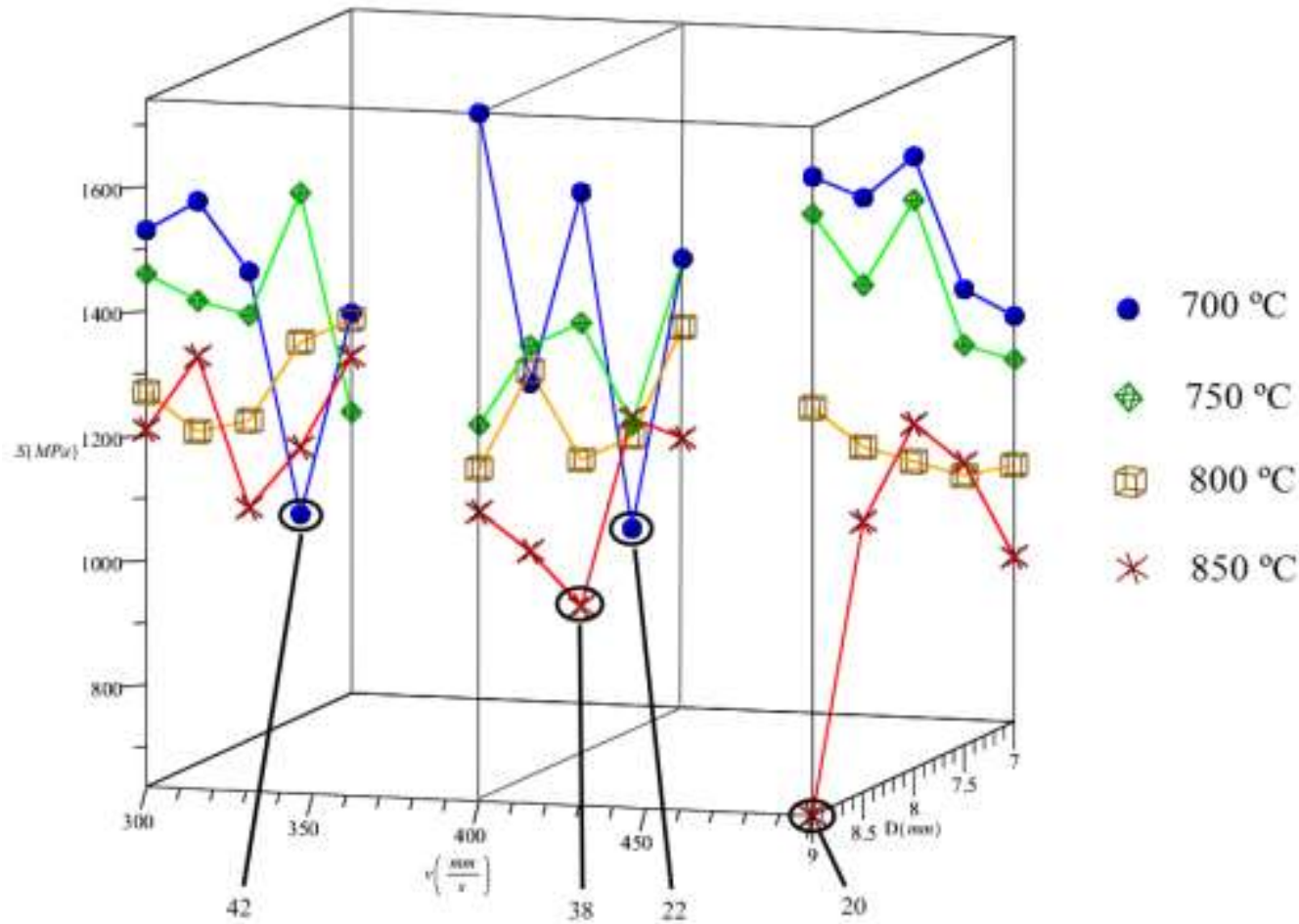

Hình 11.a: Đồ thị thể hiện mối quan hệ giữa 4 đại lượng phân tích: Đường kính phôi $(D)$, vận tốc dập $(\mathrm{mm} / \mathrm{s})$, nhiệt độ phôi $(T)$ và ứng suất dư lớn nhất $(S)$ - Xét các mặt phẳng $S$ - $D$ 


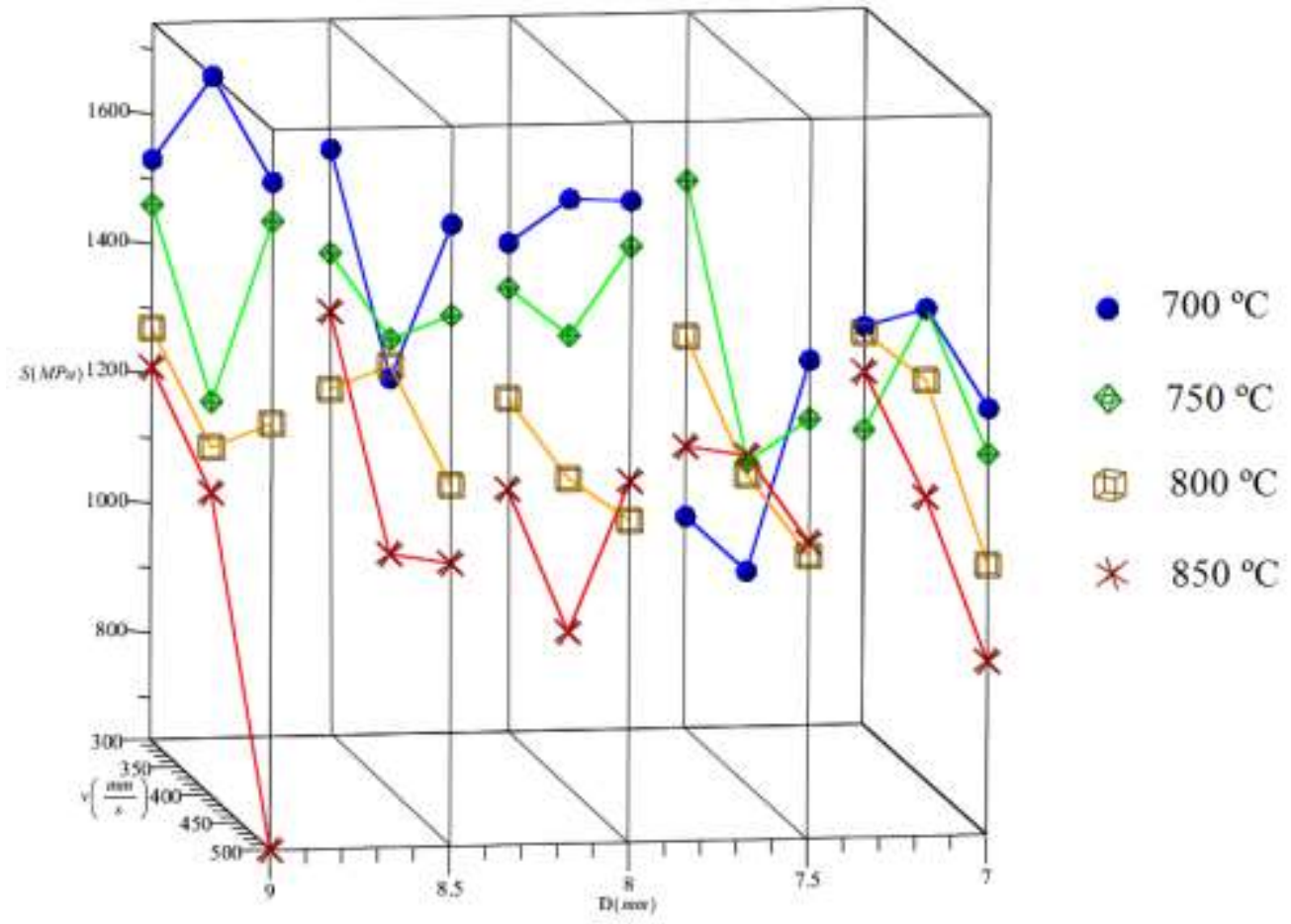

Hình 11.b: Đồ thị thể hiện mối quan hệ giữa 4 đại lượng phân tích: Đường kính phôi $(D)$, vận tốc dập $(\mathrm{mm} / \mathrm{s})$, nhiệt độ phôi $(T)$ và ứng suất dư lớn nhất $(S)$ - Xét các mặt phẳng $S$-v

Về mặt thực tiễn, thì các chuyên gia dập sẽ quan tâm đến các điểm $41,56,1,16$ vì có đường kính nhỏ nhất $D=7 \mathrm{~mm}$. Nếu cần sản phẩm với chất lượng cao (vận tốc dập nhỏ nhất) thì có 2 điểm đáng chú ý đó là 41 và 56 , trong đó nhiệt độ điểm 41 nhỏ nhất $\left(700^{\circ} \mathrm{C}\right)$ nhưng lực dập lớn nhất $(1660 \mathrm{kN})$ và nhiệt độ điểm 56 lớn nhất $\left(850^{\circ} \mathrm{C}\right)$ nhưng lực dập nhỏ nhất $(1310 \mathrm{kN})$. Nếu chất lượng sản phẩm không cần quá cao và ưu tiên năng suất (vận tốc dập lớn nhất có thể $=500 \mathrm{~mm} / \mathrm{s}$ ) thì 2 điểm đáng chú ý là 1 và 16 , trong đó nhiệt độ điểm 1 nhỏ nhất $\left(700^{\circ} \mathrm{C}\right)$ nhưng lực dập lớn nhất $(1810 \mathrm{kN})$ và nhiệt độ điểm 16 lớn nhất $\left(850^{\circ} \mathrm{C}\right)$ nhưng lực dập nhỏ nhất $(1320 \mathrm{kN})$. Tuy nhiên, đây chỉ là những lựa chọn khi ưu tiên về tiêu chuẩn lực dập, còn ví dụ như ở tiêu chuẩn ứng suất dư tối đa thì 56 điểm còn lại sẽ có thể là những lựa chọn tốt hơn.

Tương tự ở đồ thị hình 11 khi xét mối tưởng quan giữa ứng suất dư lớn nhất $S$ với 3 thông số còn lại, ta thu được 1 số nhận xét sau:

- Mối quan hệ giữa đường kính phôi và ứng suất dư lớn nhất (hình 11.a, các mặt phẳng $S-D$ ) là khá phức tạp, không tuân theo logic thông thường là đường kính càng lớn thì ứng suất dư càng lớn. Không chỉ 2 đại lượng này có sự ảnh hưởng lên nhau mà chúng còn bị chi phối bởi tốc độ dập cũng như nhiệt độ. Cụ thể, ta thấy với các tốc độ dập 300 và $400 \mathrm{~mm} / \mathrm{s}$ thì mối tương quan giữa 4 đại lượng này là phức tạp, tuy nhiên ở tốc độ nhanh nhất là $500 \mathrm{~mm} / \mathrm{s}$, với 2 nhiệt độ thấp nhất là $700^{\circ} \mathrm{C}$ và $750^{\circ} \mathrm{C}$ thì tạm thời mối tương quan $S-D$ là rõ ràng nhất, gần như cùng 1 quy luật.

- Mối quan hệ giữa vận tốc dập và ứng suất dư lớn nhất (hình $11 . b$, các mặt phẳng $S$-v) cũng rất phức tạp và không có quy luật.

Tuy nhiên về mặt thực tiễn thì nhà sản xuất cũng sẽ quan tâm tới 4 điểm 20, 22, 28, 42 (Hình 11.a) nếu xét về tiêu chí ứng suất dư để đảm bảo độ bền của sản phẩm. Điểm 20 tương ứng với đường kính $D=9 \mathrm{~mm}, v=500 \mathrm{~mm} / \mathrm{s}$ và nhiệt độ nung cũng lớn nhất $T=850^{\circ} \mathrm{C}$, tuy nhiên lại cho ra ứng suất dư nhỏ nhất $S=636 \mathrm{MPa}$. So với điểm 20 , điểm 38 tuy có ứng suất dư lớn hơn $S=874 \mathrm{MPa}$, nhưng bù lại thì vận tốc dập và đường kính lại nhỏ hơn $(D=8 \mathrm{~mm}, v=400 \mathrm{~mm} / \mathrm{s})$. Hai điểm 22 và 42 có ứng suất dư và đường kính bằng nhau $S=962 \mathrm{MPa}, D=7.5 \mathrm{~mm}$, về ứng suất lớn hơn của 2 điểm 20,38 , tuy nhiên, chúng lại có lợi thế về vận tốc cũng như đường kính. 
Ta thấy rằng, đối với mỗi tiêu chí, như lực dập và ứng suất dư, thì nhà sản xuất có thể lựa chọn 8 điểm đáng chú ý như đã nêu. Dựa vào kết quả mô phỏng và các đồ thị trực quan có thể chọn ra được những chế độ dập hợp lý này. Tương tự, việc phân tích này có thể mở rộng hơn khi xét thêm các tiêu chuẩn khác (biến dạng, xếp phôi, độ cứng, mật độ, v.v...). Chúng ta thấy rằng, mỗi một tiêu chí có ý nghĩa quan trọng khác nhau, tùy vào thời điểm nhu cầu của người tiêu dùng cũng như các bối cảnh cụ thể khác. Do đó thì quy trình mô phỏng và phân tích mà bài báo đề xuất luôn có thể giúp cho nhà sản xuất lựa chọn được các quyết định phù hợp nhất tại từng thời điểm khác nhau.

\section{KẾT LUẬN}

Phương pháp gia công dập khối nóng là một phương pháp quan trọng trong ngành gia công áp lực ở nước ta. Trong bài báo này các tác giả đã:

- Đề xuất các quy trình trình thiết kế, mô phỏng, phân tích khép kín dập nóng khối dựa trên ứng dụng các hệ thống CAD/CAE. Các quy trình này có thể áp dụng cho các lĩnh vực gia công áp lực khác, giúp tiết kiệm chi phí thực nghiệm và chế tạo nhiều loại sản phẩm đa dạng khác

- Tiến hành thực hiện 60 thực nghiệm số với các quy trình đề xuất, từ đó xây dựng được các đồ thị trực quan để đánh giá mối quan hệ, ảnh hưởng qua lại giữa các thông số dập. Kết quả cho thấy những mối quan hệ của từng cặp thông số là rất phức tạp vì chúng bị ảnh hưởng qua lại bởi các thông số khác. Do vậy trong gia công dập nóng, khó có thể dự đoán việc tang-giảm các thông số dựa trên các suy luận và kinh nghiệm thông thường, mà cần phải tiến hành mô phỏng để phân tích và đưa ra các quyết định sản xuất

- Dựa trên ví dụ 2 tiêu chuẩn là lực dập và ứng suất dư lớn nhất đã lựa chọn được 8 điểm tốt nhất, tương ứng với 8 bộ thông số dập có thể áp dụng để gia công thật về sau. Phương pháp này có thể áp dụng khi xét tới nhiều tiêu chuẩn chất lượng khác như biến dạng, xếp phôi, độ cứng, mật độ, v.v...Và khi xét những tiêu chuẩn này thì các điểm tốt nhất sẽ có thể là ở trong số 52 điểm còn lại. Nên các đồ thị trực quan có thể giúp nhà sản xuất lựa chọn các phương án dập phù hợp, từ đó tạo ra sản phẩm theo các yêu cầu khác nhau từ phía thị hiếu của khách hàng, ở các bối cảnh sản xuất cụ thể.

Bên cạnh đó, một số hướng phát triển trong tương lai là áp dụng hệ thống $\mathrm{CAM}$ để xuất ra các chương trình gia công $\mathrm{CNC}$ cho khuôn, nghiên cứu ảnh hưởng của các tiêu chuẩn còn lại để tìm được những chế độ dập hợp lý và chính xác hơn nữa, cũng như cần xây dựng các thiết bị thực nghiệm để đánh giá kết quả mô phỏng, hoặc thực hiện những mô phỏng này trên nhiều phần mềm khác nhau để kiểm chứng tính chính xác của chúng.

\section{TÀI LIỆU THAM KHẢO}

[1] Lê Nhương, Kỹ thuật Rèn và Dập nóng, Nhà xuất bản công nhân kỹ thuật, 1978, 228 tr .

[2] Ming Wang Fu, Design and Development of Metal-Forming Processes and Products Aided by Finite Element Simulation, Department of Mechanical EngineeringThe Hong Kong Polytechnic University, 2017, 258 p.

[3] Nghệ, P.V., Công nghệ dập tạo hình khối. Nhà xuất bản Bách Khoa, 2008, 276 p .

[4] Fluhrer, J., Deform 2D 8.1 version uer's manual, Scientific Forming Technologies Corporation, 2004, 288p.

[5] https://www.ansys.com/, (truy cập ngày 23/02/2018).

[6] https://www.3ds.com/products-services/simulia/products/abaqus/, (truy cập ngày 23/02/2018).

[7] Nguyễn Hữu Phước, Nghiên cứu ảnh hưởng tốc độ chày và lực dập trong quá trình gia công dập tấm, trong Luận văn Thạc sĩ. Trường Đại học Công nghiệp TPHCM, 90 tr. 2017.

[8] http://www.transvalor.com/en/cmspages/forge-nxt.32.html, (truy cập ngày 23/02/2018).

[9] http://www.qform3d.com/, (truy cập ngày 23/02/2018).

[10] http://www.enginsoft.com/about-us/, (truy cập ngày 23/02/2018).

[11] https://www.deform.com/products/deform-3d/, (truy cập ngày 23/02/2018). 
[12] http://ksg.com.vn/index.php?route=product/category\&path=33, (truy cập ngày 23/02/2018).

[13] Kao, Y.-C., H.-Y. Cheng, and C.-H. She, Development of an integrated CAD/CAE/CAM system on tapertipped thread-rolling die-plates. Journal of Materials Processing Technology, 2006. 177(1-3): p. 98-103.

[14] Lin, B.-T. and C.-C. Kuo, Application of an integrated RE/RP/CAD/CAE/CAM system for magnesium alloy shell of mobile phone. Journal of Materials Processing Technology, 2009. 209(6): p. 2818-2830.

[15] Misirli, C., Can, Y., An experimental study and designing process by using cad/cae: In combined open die forging-extrusion process of different shaped geometries from aluminum alloy samples. International Journal of Modern Manufacturing Technologies. ISSN 2067-3604, Vol. II, No. 1 / 2010.

[16] Khalilpourazary, S., et al., Design and manufacturing of a straight bevel gear in hot precision forging process using finite volume method and CAD/CAE technology. The International Journal of Advanced Manufacturing Technology, 2011. 56(1-4): p. 87-95.

[17] Coupez, T., et at., 3-D finite element modelling of the forging process with automatic remeshing. Journal of Materials Processing Technology, 27 (1991) 119-133.

[18] Loup Chenot, J., et at., Finite element modelling of forging and other metal forming processes. https://halmines-paristech.archives-ouvertes.fr/hal-00573831, (truy cập ngày 17/05/2018).

[19] https://www.3dsystems.com/software/geomagic-design-x., (truy cập ngày 23/02/2018).

Ngày nhận bài: 14/05/2018

Ngày chấp nhận đăng: 09/06/2018 